\title{
Assessment of Nutritional Status of Cancer Patients Using Scored PG-SGA Tool
}

\author{
Kavya Parasa ${ }^{1}$,Dr.Krishnaveni Avvaru ${ }^{2}$ \\ ${ }^{1}$ Final Year MBBS Student, Andhra Medical College, Visakhapatnam \\ ${ }^{2}$ Professor andHead, Department of Community Medicine, RIMS, Srikakulam
}

\begin{abstract}
:
Background:Malnutrition and weight loss are prevalent among 20-80\% of cancer patients, hence assessment of nutritional status and timely intervention curbs the mortality associated with the malnourishment of cancer. The scored PG-SGA has been accepted by the Oncology nutrition dietetic practice group of American Dietetic Association as the standard for nutritional assessment for patients with cancer.

Objectives:1)To study the socio-demographic profile of the study population. 2)To assess the nutritional status using anthropometry and PG-SGA score. 3)To identify the level of nutritional intervention required according to $P G$-SGA score.

Methodology:It is a hospital based cross-sectional study. A pretested questionnaire including the Scored PGSGA tool was administered to cancer patients attending the Radiotherapy unit of a tertiary care hospital. Study tools include scored PG-SGA questionnaire,measuring tape, weighing scale, etc. Data was collected after taking informed consent. Data was analysed using SPSS software and relevant statistical tests were applied.

Results:Total of 70 cancer patients were included. Majority were females(71.5\%)and the rest were males(28.5\%); mean age of females was 46.8 years and that of males was 43.46 years; among females Ca. breast was most common followed by Ca. Cervix; among males 55\% were with GI cancers; $48 \%$ of the patients were malnourished either excess or deficit; $43 \%$ statedthat their food intake has changed; $35.7 \%$ had PG-SGA score between 4-8 and require intervention by dietician; 20\% had score >9 and need Critical nutritional intervention. Conclusion:Scored PG-SGA tool helps to identify malnourished hospital patients with cancer and allows for triaging of patients for nutritional support.
\end{abstract}

Keywords: Cancer patients, Malnutrition, Nutritional status, PG SGA Score

\section{Introduction}

Nutritional status of any individual plays a pivotal role in maintaining the health and integrity. Among cancer patients,constant focus is maintained on the disease remission and to reduce the mortality associated with it,but the level of nutrition is often left undiagnosed.Studies indicate that malnutrition and weight loss are prevalent among $20-80 \%$ of cancer patients (1), hence assessment of nutritional status and timely intervention curbs the mortality associated with the malnourishment in cancer. The PG-SGA score, which is adopted from the SGA score, was specifically developed for patients with cancer(2).It is much more patient friendly and the patient can complete the score sheet up to the medical history, while the physical examination part can be done by the examiner. The total score from all the components will be summated,and depending upon the score obtained the level of intervention needed for the patient based upon his nutritional status can be attained. The scored PG-SGA has been accepted by the Oncology nutrition dietetic practice group of American Dietetic Association as the standard for nutritional assessment for patients with cancer(2).

The aim of this study is to assess the nutritional status of cancer patients attending the radiotherapy unit of tertiary care hospital.

\section{Methodology}

A hospital based cross sectional study was done in the department of Radiotherapy attached to King George hospital, Visakhapatnam, which is a referral hospital for north coastal districts of ANDHRA PRADESH. The study was conducted for 2 months in the year of 2013. All the cancer patients attending the above department during the study period formed the sample size. Pre-tested questionnaire was administered.Study tools include scored PG-SGA tool for assessing nutritional status, measuring tape, weighing scale etc. Data was collected after taking informed consent. Data was analysed using SPSS software and relevant statistical tests were applied.

\section{Results}

A total of 70 cancer patients who were attending radiotherapy unit were included in the study .Majority were females i.e $71.5 \%$ and the rest $28.5 \%$ were males. The age of the study population ranged from 18 years to 
72 years, with the mean age of 46.8 years for males and 43.46years for females. Majority were in the age group of 31-50 years. Majority of men were daily labourers by occupation, while $54 \%$ of women were home makers. Half of the study population were illiterates.

Table 1: Distribution Of Study Population According To Gender And Type Of Cancer.

\begin{tabular}{|l|l|l|l|}
\hline TYPE OF CANCER & MALES -n(\%) & FEMALES-n(\%) & TOTAL-n \\
\hline Ca. Breast & --- & $18(36)$ & 18 \\
\hline Ca. Cervix & --- & $16(32)$ & 16 \\
\hline Other Gynec cases & ---- & $10(20)$ & 10 \\
\hline GI cancers & $11(55)$ & $2(4)$ & 13 \\
\hline Genito urinary cancers & $2(10)$ & ---- & 2 \\
\hline Others & $7(35)$ & $4(8)$ & 11 \\
\hline TOTAL & $20(100)$ & $50(100)$ & 70 \\
\hline
\end{tabular}

Among females, patients with carcinoma breast were more i.e., $36 \%$ followed by Ca. Cervix i.e., $32 \%$.Among males $55 \%$ were patients with gastrointestinal cancers, $10 \%$ with genitourinary cancers and rest were chronic myeloid leukaemia, Nasal carcinoma, etc.

Table 2: Distribution Of Study Population According To Gender \& BMI

\begin{tabular}{|l|l|l|l|}
\hline BMI & MALES- $\mathrm{n}$ & FEMALES- $\mathrm{n}$ & TOTAL-n(\%) \\
\hline$<18.5$ & 5 & 9 & $14(20)$ \\
\hline $18.5-25$ & 13 & 24 & $37(52.8)$ \\
\hline$>25$ & 2 & 17 & $19(27.14)$ \\
\hline TOTAL & 20 & 50 & $70(100)$ \\
\hline
\end{tabular}

Nearly half $(47.2 \%)$ of study participants were malnourished i.e., either excess or deficit. $20 \%$ of patients had BMI less than 18.5 while $27.14 \%$ of patients were obese, and among whom majoritywere females.

Table 3: Gender Wise Distribution Of Study Population According To Percentage Of Weight Loss During Past 2 Weeks

\begin{tabular}{|l|l|l|l|}
\hline 1. WEIGHT & M & F & TOTAL \\
\hline Decreased & 11 & 31 & $42(60)$ \\
\hline Unchanged & 9 & 18 & $27(38.5)$ \\
\hline Increased & - & 1 & $1(1.4)$ \\
\hline TOTAL & 20 & 50 & 70 \\
\hline
\end{tabular}

Only $38.5 \%$ stated that their weight was not changed during the past 2 weeks. $60 \%$ of patients stated that their weight has decreased during the past 2 weeks. 
Table 4: Food Intake Among Study Population

\begin{tabular}{|l|l|l|l|}
\hline 2. FOOD INTAKE & M & F & TOTAL \\
\hline Unchanged & 4 & 25 & $29(39)$ \\
\hline$>$ Usual & 2 & 1 & $3(4)$ \\
\hline$<$ Usual & 14 & 24 & $38(57)$ \\
\hline TOTAL & 20 & 50 & 70 \\
\hline
\end{tabular}

When the patients were asked "as compared to your normal intake, how would you rate your food intake during the past month" $57 \%$ stated that their food intake was less than normal and $39 \%$ stated that it was not changed.

Table 5: Symptoms Among Study Population

\begin{tabular}{|l|l|l|l|}
\hline 3. SYMPTOMS & MALES & FEMALES & TOTAL \\
\hline No problems eating & 8 & 27 & $35(50)$ \\
\hline Anorexia & 5 & 13 & $18(25.7)$ \\
\hline Nausea & - & 7 & $7(10)$ \\
\hline Vomiting & - & 4 & $4(5.7)$ \\
\hline Constipation & 1 & 8 & $9(12.8)$ \\
\hline Diarrhoea & 1 & 2 & $3(4.2)$ \\
\hline Mouth sores & 1 & - & $1(1.4)$ \\
\hline Dry mouth & 3 & 7 & $10(14.2)$ \\
\hline Feel full quickly & 2 & 9 & $11(15.7)$ \\
\hline
\end{tabular}

Half of the study population stated that they had no problems eating during the past 2 weeks, where as $25.7 \%$ stated that they had no appetite and $14.2 \%$ had dry mouth which kept them away from eating.

Table 6: General Activities Among The Study Population

\begin{tabular}{|l|l|l|l|}
\hline 4. ACTIVITIES & MALES & FEMALES & TOTAL \\
\hline Normal with no limitation & 6 & 5 & $11(15.7)$ \\
\hline Fairly normal activities & 5 & 25 & $30(42.8)$ \\
\hline $\begin{array}{l}\text { In bed or chair < half the day } \\
\text { Able to do little activity ,most of the day in bed } \\
\text { or chair }\end{array}$ & 5 & 8 & $10(14.2)$ \\
\hline Pretty much bedridden ,rarely out of bed & 2 & 7 & $12(17.1)$ \\
\hline TOTAL & 20 & 5 & $7(10)$ \\
\hline
\end{tabular}

When the question was asked to rate their general activity over the past month, only $15.7 \%$ stated that their activity was normal with no limitation and $17.1 \%$ stated that they were able to do only little activity , and spend most of the day in bed or chair. 
Table 7: PG-SGA Score And Nutritional Intervention Recommended

\begin{tabular}{|l|l|l|}
\hline PG SGA Score & TOTAL(\%) & Recommendation \\
\hline $0-1$ & $16(22.8)$ & No intervention required \\
\hline $2-3$ & $15(21.4)$ & Patient and family education \\
\hline $4-8$ & $25(35.7)$ & Intervention by dietician \\
\hline$\geq 9$ & $14(20)$ & Critical nutritional intervention \\
\hline TOTAL & $70(100)$ & \\
\hline
\end{tabular}

When PG-SGA score was calculated, 35.7\% had score between 4-8 and as recommended they need intervention by dietician.One fifth $(20 \%)$ of study population had score $\geq 9$ and they require critical nutritional intervention and $21.4 \%$ had score $2-3$ and they require patient and family education.

\section{Discussion}

The present study used PG-SGA score to assess nutritional status which is considered as the best standard questionnaire used in oncologic patient's nutritional status. In our study more than half (55.7) had PGSGA score less than 4 and it indicates they require nutritional intervention either by dietician or there is an urgent need for improved symptom management. Nearly half $52.8 \%$ of study participants had BMI within normal range (18.5 to 25 ) and the rest $47.2 \%$ had malnutrition i.e., either excess or deficit. Our findings are comparable to similar studies of other countries which show malnutrition prevalence between $20-80 \%(1,2,3,5)$.

\section{Conclusion}

Scored PG-SGA tool helps to identify malnourished hospital patients with cancer and allows for triaging of patients for nutritional support. The score helps to identify nutrition impact on symptoms also. Malnutrition, because of its negative impact on treatment, prognosis and quality of life, it is always decisive in designing treatment and care packages for cancer patients.

\section{References}

[1]. N khoshnevis, F Ahmadizar, M Alizadeh ,M E Akbari ,Nutritional assessment ofcancer patients in Tehran , Iran, Asian Pacific Journal of Cancer Prevention, Vol 12,2012;13:1621-1629

[2]. J Bauer ,S Capra , M ferguson. Use of PG-SGA as a nutrition assessment tool inpatients with cancer. The Wesley research institute ,Brisbane, Australia. EuropeanJournal of Clinical Nutrition. 2002 Aug;56(8):779-85.

[3]. Breda Laky, Monica Janda ,Geoffrey Cleghorn ,Andreas Obermair, Comparison of different nutritional assessments \& body comparison measurements in detecting malnutrition amongGynecologic cancer patients. American Society for Clinical Nutrition 2008;87:1678-85.

[4]. ArribadL , hurtos L , Mila F, Fort E ,Peiro I , Predict factors associated with malnutrition from PG-SGA in head \& neck cancer patients. Nutrition Hospital 2013 Jan-Feb;28(1):155-63.

[5]. Isenring E, Bauer J, Capra S.The scored Patient-generated Subjective Global Assessment (PG-SGA) and its association with quality of life in ambulatory patientsreceiving radiotherapy. European Journal Clinical Nutrition. 2003 Feb;57(2):305-9.

[6]. MarainaRomasChaves,CarolinaBeleo-Tome,IsabelMontenerio-Grillo,MaraiCamilo,PaulaRavasco, The diversity of nutritional status in cancer : New insights, The Oncologist 2010;15;523-530 